\title{
A LITERATURA INFANTOJUVENIL E AS AMARRAS DA LITERATURA: ARTE COM FUNCIONALIDADE
}

\section{CHILDREN'S LITERATURE AND THE CONSTRAINTS OF LITERATURE: ART WITH FUNCTIONALITY}

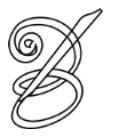

Anna Olga Prudente de OLIVEIRA*

Universidade Federal do Paraná, Brasil

\begin{abstract}
Resumo: Informado pelos Estudos Descritivos da Tradução, este artigo problematiza algumas questões centrais para a literatura infantojuvenil (LIJ) e para a reescrita desse tipo de literatura. Com base na noção de reescrita de André Lefevere e no entendimento de que aspectos ideológicos e poetológicos condicionam a publicação de obras literárias, discute-se o caráter teleológico da LIJ, bem como as imposições de ordem cultural, ideológica ou mercadológica que podem interferir na criação da LIJ ou da literatura em geral. Considera-se que para a compreensão dos fenômenos tradutórios em dada cultura meta faz-se necessário analisar, além de aspectos literários, as condicionantes particulares dessa cultura, observando especialmente as propostas ou concepções de literatura e de sociedade por parte daqueles que atuam no processo de elaboração e difusão das reescritas. Observase ainda que diferentes perspectivas ideológicas e poetológicas podem ser entrevistas não somente na diacronia que separa as reescritas mais antigas das contemporâneas, mas também as reescritas publicadas em um mesmo momento histórico poderão apresentar propostas distintas, as quais são concretizadas, por meio de estratégias tradutórias, na própria reescrita, no modo de reler o Outro. Para isso, o artigo ilustra com exemplos concretos a discussão teórica apresentada, sendo abordados casos de projetos tradutórios em sistemas literários distintos, especificamente, Estados Unidos, Polônia e Brasil. Ao discutir as implicações de uma "literatura para" e abordar as fronteiras porosas entre os termos usualmente utilizados na reescrita de LIJ (tradução, adaptação, história recontada), este trabalho objetiva abordar a complexidade da LIJ quanto a sua própria definição e as suas formas de apresentação em detrimento de perspectivas que inserem a LIJ em uma posição de inferioridade ou à margem da literatura.
\end{abstract}

Palavras-chave: Estudos Descritivos da Tradução. Reescrita. Tradução e Adaptação. Literatura infantojuvenil traduzida.

\begin{abstract}
Informed by Descriptive Translation Studies, this article raises some central questions concerning children's literature and its rewriting. Based on Andre Lefevere's notion of rewriting and on the understanding that ideological and poetological aspects restrict the publication of literary works, the teleological nature of children's literature is discussed, as well as the cultural, ideological and market demands that may interfere in the development of children's literature or literature in general. For translation phenomena to be comprehended in a specific target culture, it is necessary to analyse not just literary aspects, but also the particular constraints of that culture, observing especially the propositions or conceptions of literature and of society held by those engaged in the preparation and promotion of such rewritings. Additionally, different ideological and poetological perspectives can be seen not only in the diachrony that separates older rewritings from contemporary ones, but also in the rewritings published in the same historical period, which may present different proposals that are materialised through different translation strategies in the rewriting itself, in the way of rereading the Other. These theoretical considerations are illustrated with concrete examples of translation projects in distinct literary systems, namely the United States, Poland and Brazil. By discussing the implications of a "literature for" and the permeable borders between the terms usually used in the rewriting of children's literature (translation, adaptation, retelling), this work seeks to address the complexity of children's literature with its own definitions and forms of presentation, rather than a perspective that would place children's literature in a position of inferiority or apart from literature.
\end{abstract}

OLIVEIRA, Anna Olga P. de. A literatura infantojuvenil e as amarras da literatura: arte com funcionalidade. Belas Infiéis, Brasília, v. 8, n. 3, p. 179-199, 2019. 
Keywords: Descriptive Translation Studies. Rewriting. Translation and Adaptation. Translated children's literature.

RECEBIDO EM: 20 de fevereiro de 2019

ACEITO EM: 04 de maio de 2019

PUBLICADO EM: julho 2019

\section{Introdução}

literatura infantojuvenil (LIJ, doravante) usualmente é caracterizada por seu aspecto
teleológico, uma literatura que pressupõe um destinatário específico - a criança ou o
jovem. Seu conceito duplamente constituído gera ambiguidades inevitáveis. Se, por um lado, considera-se literatura um termo que diferencia um texto dos demais, alçando-o a uma independência de caráter artístico ou estético, por outro, a segmentação do público alvo embute na terminologia um aparente paradoxo. Um ser em formação, dependente do adulto para adquirir conhecimentos e cultura, tal é o modo como a criança ${ }^{1}$ é percebida socialmente.

180 Assim, a leitura de uma obra feita por uma criança irá envolver um processo de aquisição da cultura e da língua, colocando a literatura infantil à margem de qualquer definição não funcional de literatura (HUNT, 2013, p. 85). Como algo considerado literatura pode ser objetivamente constituído com o propósito de atender e agradar a um público caracterizado por restrições de ordem cognitiva e cultural? O paradoxo exposto é calcado em um entendimento de literatura como algo especial, mais elevado, livre de restrições ou condicionamentos, o que por sua vez contribui para a ideia de um valor intrínseco da obra literária; sua qualidade estaria no texto em si, independente de relações de poder e de cultura que julgam conveniente situá-la de tal modo (HUNT, 2013, p. 20).

Essa percepção contribui para a manutenção do lugar periférico tradicionalmente ocupado pela LIJ no sistema literário e, do mesmo modo, pela LIJ traduzida no sistema tradutório/literário. A dicotomia estabelecida entre uma literatura e uma literatura para tornase possível tanto por uma idealização da própria literatura em geral, como se obras e autores não estivessem necessariamente atrelados (e submetidos) a certas concepções de mundo (ideológicas, literárias etc.) por parte da sociedade e cultura a que pertencem, como também, por outro lado, por uma vulgarização da LIJ, classificação que por vezes abarca indistintamente toda espécie de obra voltada para a criança. Entretanto, se as restrições ou imposições de ordem cultural, ideológica ou mercadológica se encontram mais aparentes quando se trata de LIJ, a 
literatura por sua vez também está sujeita a imposições de mesmo tipo, em grau distinto.

Em todo sistema literário/tradutório, as mesmas obras estrangeiras podem vir a ser publicadas com grandes diferenças, de acordo com certas políticas editoriais, as quais muitas vezes não são de conhecimento do público leitor. No sistema literário brasileiro, conforme aponta John Milton, por exemplo, no período de 1943 a 1976, clássicos e outras obras estrangeiras, publicados no Brasil pelo Clube do Livro, recebiam traduções indiretas (quando o original não era em francês ou inglês) e tinham partes censuradas ou alteradas, sobretudo a partir de 1964 com o governo militar, caso a obra "[contivesse] material politicamente ofensivo ao regime militar, quando tinha referências escatológicas ou sexuais ou quando era necessário reduzir o original ao número padrão de páginas" (MILTON, 1996, p. 47). Realidade distinta da atual (século XXI), em que o mercado editorial privilegia traduções integrais, e sempre que possível diretas, de clássicos ou outras obras literárias. O público leitor brasileiro costumava ler as "mesmas" obras que podemos ler hoje em traduções que apresentavam cortes significativos do texto fonte, sem necessariamente estar ciente dos tipos de manipulação envolvidos na produção literária. As restrições ou imposições que ocorrem na literatura, seja em forma de censura ou de escolha de determinadas obras a serem traduzidas, por exemplo, nem sempre são vistas como formas de guiar os leitores por certos caminhos em detrimento de outros; já quando se trata de LIJ as restrições ou imposições costumam ser mais facilmente explicitadas e criticadas, gerando a desqualificação dessa literatura definida por seu aspecto funcional, uma literatura para.

Obras literárias consideradas da mais alta qualidade não são publicadas por um suposto valor intrínseco, por mais que o público leitor assim o considere, mas sim por políticas editoriais (ou institucionais, governamentais etc.) condicionadas por diversos fatores ideológicos e poetológicos (LEFEVERE, 1992). Tomando mais um exemplo na área da tradução literária, editoras podem vir a escolher ou a ter interesse apenas em certas obras que representem "melhor" o país do texto fonte, gerando assim na cultura meta uma visão homogênea dominante acerca da cultura estrangeira e, eventualmente, perpetuando estereótipos. Isso pode ocorrer quando uma cultura meta traz para seu sistema literário um leque restrito de obras de uma literatura estrangeira. Conforme aponta Lawrence Venuti, em "A Formação de Identidades Culturais",

a seleção de textos estrangeiros e o desenvolvimento de estratégias de tradução podem estabelecer cânones peculiarmente domésticos para literaturas estrangeiras, cânones que se amoldam a valores estéticos domésticos, revelando assim exclusões e 
admissões, centros e periferias que se distanciam daqueles existentes na língua estrangeira. (VENUTI, 2002, p. 130).

Desde a escolha dos textos a serem traduzidos, passando pelas estratégias de tradução até as diferentes formas de publicação, leitura e crítica da obra traduzida, uma literatura estrangeira pode ser inserida em uma cultura meta de modo a formar um cânone que não vigore na cultura de origem. Apresentado por Venuti, um caso ilustrativo de tal situação é a imagem da ficção moderna japonesa que foi consolidada nos Estados Unidos e, consequentemente, em outras culturas, tendo em vista que muitas traduções para outras línguas são feitas a partir das traduções em inglês. Durante as décadas de 1950 e 1960, a representação da cultura japonesa no sistema literário estadunidense seguiu um estereótipo bem definido, responsável por gerar para o público leitor a percepção de uma cultura "tipicamente" japonesa que se destacava como taciturna e melancólica, atribuindo ao Japão a imagem de uma terra exótica e nostálgica de seu passado. No entanto, “[tal] nostalgia expressa pelo cânone foi distintamente americana, não necessariamente compartilhada por leitores japoneses" (VENUTI, 2002, p. 139).

Essa visão hegemônica acerca da cultura nipônica consolidou-se por uma conjunção de fatores atrelados tanto à patronagem quanto aos reescritores. Segundo Edward Fowler (1992), grandes editoras lançaram no período muitas traduções de romances e coletâneas de contos focalizando poucos escritores, os quais eram representativos do gosto de uma comunidade cultural específica: acadêmicos especialistas em literatura japonesa. Tradutores como Donald Keene, Edward Seidensticker e Ivan Morris voltaram-se para autores japoneses vivos, inserindo-os no imaginário do público leitor, ao publicar vários títulos dos mesmos escritores. Desse modo, Tanizaki, Kawabata e Mishima passaram a ser uma espécie de triunvirato da ficção moderna japonesa, tornando-se, inclusive, o padrão esperado para outros autores e obras japonesas. Embora existissem outros escritores traduzidos, o impacto da ficção japonesa em tradução ficou restrito, uma vez que esses outros tinham pouca ou nenhuma visibilidade (publicados por editoras pequenas, não expostos em livrarias etc.) (FOWLER, 1992, p. 8). A formação desse cânone particular teria servido a um contexto político, em um período de Guerra Fria, no qual se fazia necessário estabelecer determinada imagem do Japão: a de uma terra exótica e nostálgica de seu passado. Já no final da década de 1980, uma nova geração de escritores e leitores de língua inglesa começa a abrir novas possibilidades de leitura da cultura e da literatura japonesas, iniciando então um processo de reformulação do cânone (VENUTI, 2002, p. 141).

Portanto, seja na literatura ou na literatura traduzida, problematizar o entendimento de 
que obras e autores são publicados tão somente por sua qualidade torna-se relevante não apenas para que se possa compreender os diversos fenômenos relacionados à LIJ nos sistemas em que atua, mas também para uma compreensão menos idealizada da literatura, que, como qualquer outro fenômeno sociocultural, não depende apenas de um talento autoral, mas está sujeita a normas e imposições de ordem ideológica e poetológica. Todo texto é marcado pela cultura em que se insere, não possuindo assim um caráter universal em si mesmo; são as pessoas, as culturas, que atribuem valor à obra, estabelecendo cânones que só serão mantidos enquanto outras pessoas e culturas continuarem a validá-los. Por isso, como afirma Peter Hunt,

não podemos falar de um "melhor" abstrato, apenas de diferenças. Em outras palavras, o status de um texto, o que lhe confere "qualidade", não é mais visto como algo intrínseco, mas simplesmente - ou complexamente - como uma questão de poder de grupo: um texto é um texto e o modo como o percebemos é uma questão de contexto. (HUNT, 2013, p. 35).

Nesse sentido, a noção de cânone é vista como uma construção social, e a literatura pode ser entendida como "a escrita autorizada e priorizada por uma minoria influente" (HUNT, 2013, p. 87). A própria noção de literatura é ideológica, ligada à questão do poder; o conceito de literatura pode ser entendido, conforme aponta Roberto Reis, em seu artigo "Cânon",

como uma prática discursiva, entre outras, dentro da ordem do discurso. Ao invés de enfrentá-lo desde uma ótica ontológica - ou seja, como se fosse possuidor de uma inerente especificidade -, passaríamos a enfocá-lo desde um ângulo funcional - ou seja, dependendo da função que se lhe conceda. Um texto não é literário porque possua atributos exclusivos que o distinguem de outro texto, mas porque os leitores (entre eles incluídos os críticos), por inúmeras razões, o vêem como tal. (REIS, 1992, p. 72).

O texto literário não surge de uma composição estética ou estilística intrinsecamente literária, mas do entendimento ou aplicação de tal texto como peça literária, a partir de critérios hegemônicos em dada sociedade acerca do que seja literatura. Assim, diários e cartas eventualmente podem tornar-se literatura, bem como obras populares criadas para consumo imediato (pornografia, romances policiais, etc.) podem vir a ser consideradas literatura, “quando passam a ser lidos por um público para o qual não eram destinados e para um propósito diferente" (HUNT, 2013, p. 87). E, por outro lado, determinadas formas de escrita ou de linguagem podem vir a ser criadas como formas literárias ou poéticas, quando há um contexto que permita e enseje tal entendimento, podendo essas novas propostas serem ou não aceitas como literatura. Pensemos, por exemplo, na poesia concreta, uma linguagem possível de ser 
criada e considerada como forma poética no contexto da segunda metade do século XX. Desse modo, a literatura é forjada por relações de poder que serão mais ou menos perceptíveis de acordo com as propostas de manutenção de um status quo ou de quebra de valores e paradigmas.

Com o entendimento de que não há um valor intrínseco ao que seria o literário, não se propõe aqui deslegitimar aquilo que uma sociedade ou seus indivíduos particularmente consideram literatura ou as grandes obras universais. Apenas busca-se enfatizar que essas percepções estão sujeitas a mudanças e, eventualmente, a grandes transformações, ressaltandose ainda que a existência de classificações é circunstancial, sendo portanto passível de questionamentos. Na discussão sobre obras para crianças e jovens teremos sempre portanto um problema à vista: a LIJ é uma literatura em que o aspecto funcional está presente na própria designação, sendo sua elaboração determinada por concepções vigentes em dada sociedade sobre o público a que se destina: a criança ou o jovem. Mas tal aspecto, entretanto, não impede a análise da LIJ enquanto literatura, uma vez que qualquer literatura está sujeita a direcionamentos, limitações ou dirigismos, em graus variáveis.

Dessa forma, uma obra para ser LIJ deveria atender aos critérios que dada sociedade 184 utiliza para a conceituação de literatura. Em consequência, no rol de livros para crianças haveria LIJ e outras obras: didáticas, educativas, recreativas etc. Nas palavras de Cecília Meireles, "um livro de Literatura Infantil é, antes de mais nada, uma obra literária. Nem se deveria consentir que as crianças frequentassem obras insignificantes, para não perderem tempo e prejudicarem seu gosto" (MEIRELES, 2016, p. 72). Meireles, portanto, diferencia a LIJ de outras obras também voltadas para crianças, tecendo ainda uma crítica radical às obras que considera sem importância. Assim como obras para adultos podem ser consideradas literatura ou excluídas dessa classificação, o mesmo ocorre com as obras para crianças ou jovens.

Podemos então pensar em algumas circunstâncias em que obras ou fenômenos socioculturais não surgiram como LIJ, mas tornaram-se uma literatura para o público infantojuvenil, em um processo de ressignificação ou nova leitura realizado por autores, por responsáveis pela difusão de tais obras, ou, ainda, pela forma como o público acabou interagindo com esses textos. Um primeiro exemplo é o caso notório de tradições orais que se tornaram literatura escrita, a partir do século XVII, com autores como Charles Perrault, Mme. D’Aulnoy, La Fontaine ou, posteriormente, os irmãos Grimm, que recriaram ou fizeram suas próprias leituras de lendas, contos populares, contos de fadas e fábulas. Nos contos de Perrault, por exemplo, o autor desenvolve elementos (personagens e situações) na narrativa, realizando algumas transformações a partir das fontes populares ou literárias que utiliza. E, da mesma 
forma, muitas reescritas posteriores dos contos do escritor francês excluem ou censuram tais elementos por não serem considerados apropriados ao público alvo, em um processo contínuo de ressignificação, de acordo com valores da época e concepções de criança e, consequentemente, de LIJ. Outro caso de obras que não surgiram como LIJ é o dos "livros não escritos para as crianças, mas que vieram a cair nas suas mãos, e dos quais se fizeram depois adaptações, reduções, visando torná-los compreensíveis ou adequados ao pequeno público" (MEIRELES, 2016, p. 52). Como exemplifica Meireles, o livro Viagens de Gulliver, de 1726, de Jonathan Swift, a princípio uma sátira aos partidos políticos da Inglaterra,

foi lido por toda gente, desde os estadistas até as "nurses". Cada um o entendeu como pôde, ou como quis. Tal é a sorte de muitos livros. As imagens passaram a viver por si mesmas livres do autor, teceram sua história, ao gosto da sensibilidade dos leitores. Que fazer, quando as personagens adquirem tal força, e podem emancipar-se? O leitor de hoje, sem saber nada da Inglaterra de Jorge I, continua a divertir-se ou a meditar, enquanto Gulliver viaja pela terra dos gigantes e dos pigmeus [...]. (MEIRELES, 2016, p. 55, grifo nosso).

A sensibilidade dos leitores... as crianças. Para Meireles, não teríamos uma LIJ constituída aprioristicamente, mas a posteriori. O público infantil definiria assim o que seria LIJ: obras pelas quais se interessa e que lê com prazer (MEIRELES, 2016, p. 15). Não obstante, cabe observar que uma vez livres do autor as imagens sobrevivem por outras perspectivas que as condicionam a novas leituras e percepções, seja a sensibilidade e o interesse das crianças ou as intenções/propostas dos adultos, permeadas por concepções de mundo e de literatura vigentes.

A escrita de LIJ, portanto, caracteriza-se por esta assimetria inescapável: são os adultos que criam as obras para crianças. E, ainda, são os adultos (pais, educadores etc.) que escolhem as obras para o público infantil, podendo realizar uma censura a certos trechos considerados inadequados quando leem as histórias em voz alta, exercendo um controle final sobre o conteúdo dos livros ao omitir certas partes ou acrescentar outras, eventualmente. A assimetria relativa ao processo de criação literária pode significar um obstáculo à adoção de critérios igualitários para compreensão, análise ou crítica da LIJ enquanto literatura. Se a intencionalidade declarada e a hierarquia instituída - o domínio, em todos os níveis, do adulto sobre a criança - balizarem a escrita da LIJ, a obra será carregada de tintas com fins utilitários ou moralistas e apagada de tons literários, isto é, daquilo que se considera literatura no momento da escrita.

Porém, apesar da assimetria, trata-se de uma relação, pois o adulto não pode prescindir 
do interesse da criança pelas obras que lhe são destinadas. O público leitor interage, afirma suas preferências, busca na literatura "[posicionar-se] diante do real, que se dá a ele de modo fragmentário e descontínuo" (ZILBERMAN, 2003, p. 57). A experiência literária não é equivalente à experiência no âmbito da escola ou da família. Embora não possamos saber como as crianças leem uma obra, se como experiência estética ou de modo funcional, ou ambos, uma diferenciação faz-se necessária: cabe à LIJ ser literatura e não pedagogia, porquanto "é decisivo para a sobrevivência do gênero que responda a essas solicitações [as expectativas da criança] por intermédio de suas singularidades literárias" (ZILBERMAN, 2003, p. 57).

Em consonância com Cecília Meireles, entendo que a criança não tem acesso à LIJ apenas para ganhar o conhecimento da cultura e da língua ou para a diversão, mas pode além disso ter acesso à diversidade, a experiências literárias, a propostas de escrita, a estilos, resultando em uma interação com o texto, sob uma perspectiva não limitada ao aspecto funcional do aprendizado. Nesse sentido, as restrições comumente encontradas no âmbito da LIJ são inadequadas por serem forjadas no intuito de que a criança deva apenas ter acesso a obras para aprender algo, adquirir o conhecimento que não possui etc., e não para desenvolver suas próprias capacidades e interesses, construindo um imaginário próprio a partir da experiência literária. $\mathrm{O}$ controle e a limitação nos textos para crianças, restringindo conteúdo e forma ao que se considera que elas podem entender ou ter acesso, apenas mina as possibilidades de interação com o texto. Propostas contemporâneas de facilitação ou de adequação de obras ao "mundo de hoje", realizadas através de censura de termos considerados inadequados ou do esclarecimento de palavras difíceis em obras de autores brasileiros, como Monteiro Lobato e Machado de Assis, podem aproximar de modo pragmático o leitor do texto, porém, ao mesmo tempo, o afasta da experiência literária, do contato com autores e obras distintos, da diversidade, da experiência com aquilo que é outro. Considerar que a criança ou o jovem simplesmente não tem capacidade para compreender o que lhe é apresentado, podendo inclusive com isso adotar modelos de comportamento inadequados, talvez seja mais fácil do que desenvolver um trabalho de atenção às demandas desse público, as quais só podem ser conhecidas na relação daqueles que lidam com a literatura.

Devido a uma atenção necessária às demandas próprias do público infantil, o ponto de partida para a criação ou reescrita de LIJ está na “interação com quem escreve - o autor e o autor-tradutor - e com quem lê; [uma] interação, enfim, com o entorno que lhe deu origem, com as referências ao universo eminentemente cultural que lhe serve de fundo" (AZENHA JUNIOR, 2005, p. 372). Tal proposta dialógica, defendida por João Azenha Junior, encontra 
ecos na explanação de Ana Maria Machado sobre a questão da ideologia da leitura, "a carga que o leitor traz ao ato de ler" (MACHADO, 2016, p. 18). Como exemplo, a escritora comenta as diferentes leituras de seu livro infantojuvenil Menina bonita do laço de fita, uma história inspirada em uma situação familiar. A personagem criada por Machado foi inspirada na filha, uma menina branca. Porém, ao transformar seu texto em literatura, ela mudou a ideia de uma menina linda e loura para uma menina linda e preta, tema que considerou mais condizente com a realidade brasileira. A obra obteve grande sucesso e reconhecimento na América Latina, além de ter sido fonte de inspiração para brasileiras negras, conforme relato de uma de suas leitoras. No entanto, algumas leituras foram radicalmente distintas, por exemplo, a da professora primária que, em um debate nos Estados Unidos, considerou espantoso que a autora "tivesse a coragem de associar numa mesma história uma menina negra e um coelho, quando todos sabem que o coelho é um símbolo de promiscuidade sexual e de proliferação, e que essa associação era ofensiva aos negros" (MACHADO, 2016,, p. 22).

Podemos assim considerar que "um livro não é apenas aquilo que está escrito nele, mas também [sobretudo] a leitura que se faz desse texto" (MACHADO, 2016, p.23). Tal como Ana Maria Machado propõe, um livro não é ponto de chegada, mas ponto de partida permanente para outras leituras. E assim podemos pensar em termos de LIJ, uma literatura que possibilita novas e futuras leituras (sem se fechar em uma prescrição), mas que também pode propiciar uma viagem de volta, quando o adulto entra nesse jogo e lê, ou lê novamente (mais uma vez e de modo novo), a LIJ.

Embora a denominação apresente o paradoxo de uma literatura definida por sua funcionalidade, a LIJ é entendida aqui como literatura no sentido de diferenciação de diversas outras escritas também voltadas ao público infantojuvenil e, mais ainda, no sentido de que a LIJ apresenta características literárias, tais como estas sejam entendidas em dada sociedade. Consequentemente, concepções distintas de literatura marcam as formas como os textos serão reescritos em épocas distintas.

\section{A literatura infantojuvenil reescrita}

Tendo em vista a complexidade das questões envolvendo a conceituação de LIJ e sua problematização, pensar sobre a reescrita de LIJ é do mesmo modo um tema que envolve muitos meandros. Cabe aqui inicialmente apontar para o problema de que, se o entendimento de LIJ em dado sistema literário envolve questões culturais e sociais bem como as de caráter literário propriamente, quando essa literatura é reescrita em outro sistema literário também será marcada 
ou condicionada por uma série de aspectos da cultura meta, tanto de ordem social quanto estética, como a questão da definição de literatura. Haverá assim uma relação de tensão entre aspectos considerados literários, responsáveis por instigar a elaboração de reescritas literárias em dada cultura, e as condicionantes particulares dessa cultura meta, responsáveis por concretizar uma releitura da obra (a reescrita) em dado momento histórico do sistema literário meta. Como aponta Azenha,

\begin{abstract}
essa relação de tensão que, em maior ou menor grau, está presente na tradução de qualquer obra literária, adquire especificidade na tradução de LIJ no momento em que a atenção se volta para os agentes responsáveis pela realização dessa releitura, dessa atualização. Em outras palavras, não apenas no tema e não apenas na concretude da forma estariam, de partida, as questões que articulam a LIJ com as diversas vertentes dos Estudos da Tradução, mas sim na intermediação, no momento em que os sujeitos envolvidos - entendidos esses sujeitos não apenas como o tradutor e o editor, mas como uma gama de agentes (leitores, educadores, pais, entre outros) - se defrontam com a questão de como reler o Outro, o que é estrangeiro e diferente, e de como formatar sua leitura, a fim de apresentar o Outro a um grupo de destinatários com características específicas, ainda que não totalmente conhecidas. (AZENHA JUNIOR, 2015, p. 212-213, grifo nosso).
\end{abstract}

Essa intermediação é o ponto chave subjacente à peculiaridade da LIJ, a seu traço distintivo - a questão do destinatário, envolvendo tanto o público alvo (crianças e jovens) como inextricavelmente os responsáveis pela elaboração, divulgação e aquisição das obras (adultos: editores, reescritores, educadores, pais, leitores). Portanto, quando se trata de reescrita de LIJ, a questão de como reler o Outro, característica de toda reescrita, é potencializada a um grau maior envolvendo o próprio entendimento que se tem em relação à infância em dada cultura meta, passando pela questão do equilíbrio entre a utilidade e o prazer proporcionados pela LIJ a seu público, e alcançando ainda questões mais amplas tais como concepções de sociedade e de literatura.

Sob esse aspecto, um caso emblemático é trazido por Monika Wozniak, ao tratar da reescrita de um dos contos de fadas mais célebres da LIJ no sistema literário da Polônia. Em seu artigo "Where (and When) Do You Live, Cinderella? Cultural Shifts in Polish Translations and Adaptations of Charles Perrault's Fairy Tales", Wozniak (2013) aponta para uma questão central no que concerne a uma obra literária, ao mostrar como diversos elementos dos contos de Perrault estavam relacionados ao contexto literário e social específico do autor francês do século XVII. Assim, ainda que venha a receber posteriormente um status canônico universalizante, como é o caso de Cinderela e de outros contos de fadas, uma obra é marcada por seu contexto e, portanto, "o comprometimento com o entorno é o que faz com que certos 
temas possam parecer anacrônicos e desatualizados a algumas culturas e perfeitamente pertinentes e inéditos em outras" (AZENHA JUNIOR, 2015, p. 214).

Nesse sentido, embora os contos de Perrault, assim como os de Andersen e os dos irmãos Grimm, por exemplo, tenham se tornado mundialmente conhecidos, sendo considerados integrantes do cânone da LIJ, Wozniak ressalta que "a própria noção de um cânone internacional de contos de fadas clássicos é falaciosa, dadas as numerosas divergências que podem ser detectadas em termos de nação, cultura, linguagem, estilo, seleção, e história" ${ }^{1}$ (WOZNIAK, 2013, p. 88, tradução nossa). A autora apresenta o contexto histórico e político da Polônia para buscar compreender o modo como Perrault tem sido apresentado ao público leitor polonês, desde as primeiras reescritas, no século XIX, em que os reescritores criavam seus próprios contos derivados dos contos de fadas, sem especificar texto fonte ou autoria. Ressaltando a prática da adaptação como uma tradição literária na Polônia desde o século XVI e XVII, Wozniak considera uma decorrência lógica que, ao final do século XIX e início do século XX, muitos escritores que empreenderam a tarefa de traduzir contos literários canônicos para o polonês não apenas não hesitaram em alterar o texto original livremente como também consideraram essa atitude natural e desejável. Com frequência, eles também atribuíam a si próprios a autoria da história recontada, outra característica da literatura infantil polonesa (WOZNIAK, 2013, p. 90). Vemos que nesse contexto o entendimento de literatura pressupõe a adaptação e não, por exemplo, um ideal de manutenção das características autorais, formais ou estilísticas de um texto.

No conto Cinderela, Perrault situa a história em um contexto específico, ornando sua narrativa com uma série de elementos relevantes à sociedade francesa da época, na qual a grande aspiração de um homem nobre seria pertencer à corte, enquanto a de uma mulher nobre seria a de pertencer à casa real ou mesmo conseguir atrair a atenção do próprio rei, vindo a tornar-se sua amante (WOZNIAK, 2013, p. 92). O conto se insere em tal contexto, no qual o modelo feminino seguia parâmetros estabelecidos pela monarquia francesa. Como ressalta Wozniak, há uma diferença radical entre essa cultura francesa e a polonesa, em que o modelo feminino tradicional relaciona-se não a uma dama da corte mas, ao contrário, a uma dona de casa trabalhadora, ligada ao campo, com uma vida simples e harmônica em relação à natureza. Tais ideais distintos, somados ao interesse de preservação de uma identidade nacional e à prática estabelecida de "tradução livre" na Polônia, fizeram com que escritores poloneses pudessem operar uma transformação radical na Cinderela de Perrault (WOZNIAK, 2013, p. 93). São feitas modificações diversas, incluindo uma nova caracterização do cenário e dos 
personagens: Cinderela passa a ser uma camponesa que encarna as virtudes domésticas mais desejáveis - honestidade, modéstia, seriedade etc.

Sob uma perspectiva diacrônica, Wozniak comenta algumas reescritas de Cinderela e também de outros contos de Perrault e analisa diversos fatores que influenciaram a questão de como reler o Outro no sistema literário/tradutório polonês, concluindo que

embora seja lamentável que uma edição crítica das obras de Perrault na Polônia ainda não tenha sido publicada, o caso específico da recepção polonesa de seus contos pode ser interpretado como um fascinante e particular caso de nacionalização dos contos de fadas clássicos. ${ }^{2}$ (WOZNIAK, 2013, p. 96, tradução nossa).

Nesse caso, a partir da análise feita por Wozniak, considero que a Cinderela polonesa dá continuidade ao status canônico do conto de Charles Perrault, realizando, entretanto, uma assimilação do Outro a sua cultura doméstica, nacional. Se toda reescrita realiza esse processo de algum modo, no caso das reescritas dos contos de Perrault na Polônia, uma proposta ideológica nacionalista e de enaltecimento de valores domésticos exerceu uma atuação bastante forte na poética adotada por reescritores responsáveis por transformações no texto. Os valores ideológicos são expressos assim pela concretização na escrita da transformação do exótico ou do diferente em algo familiar e desejável.

Tais liberdades de manipulação da obra de Perrault estão associadas a questões histórico-sociais da cultura meta, mas também à própria caracterização da LIJ e sua consequente posição periférica em termos literários, por se tratar de uma literatura segmentada, conforme já abordado. O caráter didático tradicionalmente entrevisto na LIJ e as restrições necessárias considerando-se o nível de conhecimento da criança permitem ao reescritor manipular o texto de várias formas, realizando alterações, acréscimos ou diminuições, desde que, conforme ressalta Zohar Shavit, as formas de manipulação sigam dois princípios em que a tradução para crianças se baseia:

\footnotetext{
uma adequação do texto para torná-lo apropriado e útil à criança, de acordo com o que a sociedade considera (em certo momento histórico) "bom para a criança" em termos educativos; e uma adequação de enredo, caracterização e linguagem para as percepções prevalecentes da sociedade acerca da capacidade de leitura e compreensão da criança. ${ }^{3}$ (SHAVIT, 2006, p. 26, tradução nossa).
}

A partir dessas questões aqui discutidas, observa-se que para a compreensão dos fenômenos tradutórios em dada cultura meta faz-se necessário analisar, além de aspectos literários, as condicionantes particulares dessa cultura, observando especialmente as propostas 
ou concepções de literatura e de sociedade por parte daqueles que atuam no processo de elaboração e difusão das reescritas de LIJ. Cabe ressaltar, entretanto, que diferentes perspectivas ideológicas e poetológicas podem ser entrevistas não somente na diacronia que separa as reescritas mais antigas das contemporâneas; também as reescritas publicadas em um mesmo momento histórico poderão apresentar propostas distintas, as quais são concretizadas, por meio de estratégias tradutórias, na própria reescrita, no modo de reler o Outro. Em cada reescrita esse modo de reler o Outro por vezes pode ser anunciado ou percebido tendo em vista sua própria classificação ou forma de apresentação, seja como tradução, adaptação ou história recontada, por exemplo. Todavia, essas definições, vistas usualmente em qualquer edição, apresentam ambiguidades, fronteiras permeáveis e mesmo sobrepostas, gerando especialmente no campo da LIJ uma questão: até que ponto tais definições são necessárias em termos classificatórios e até que ponto são feitas apenas como forma de criar ou impor certas delimitações às reescritas, como, por exemplo, delimitações de caráter mercadológico. A seguir, abordo tais conceituações.

\section{Tradução, adaptação ou história recontada?}

Embora possam servir como guia para o leitor saber com que tipo de texto está lidando, é preciso notar que o entendimento de tradução, adaptação, reconto ou história recontada pode ser variável em épocas distintas e, ainda, em uma mesma época podemos ter a utilização de um mesmo termo para reescritas cujas estratégias e propostas tradutórias sejam distintas, aspecto que ressalta a ambiguidade presente nas nomenclaturas dadas. Em termos gerais, enquanto a tradução é vista como um texto meta que estabelece uma relação mais estrita com determinado texto fonte, a adaptação é entendida como uma representação do texto fonte em que se pressupõe uma relação mais frouxa ou distante, devido a omissões, acréscimos, alterações formais e/ou semânticas, com o objetivo de alcançar propósitos específicos. Desse modo, uma reescrita pode ser apresentada como adaptação considerando-se esse fator mencionado: o de, em teoria, afastar-se do texto fonte, por motivos variados; o que pode ser visto tanto em uma reescrita mais instrumental, com o intuito de possibilitar uma compreensão da obra por parte do público alvo, como também em uma reescrita mais autoral, em que o reescritor realize uma recriação da obra, apresentando uma nova leitura ou novas características literárias. Entretanto, conforme ressalta Lauro Maia Amorim, não há limites nítidos ou "naturais" entre reescritas apresentadas como tradução e como adaptação, não havendo "unanimidade teórica quanto à possibilidade de delimitação objetiva" (AMORIM, 2005, p. 41). 
A maior liberdade de manipulação textual característica das adaptações muitas vezes relega aos textos assim apresentados um status de desprestígio no âmbito da literatura, pela pressuposição de um caráter funcional para o texto meta, como, por exemplo, a proposta de adequação ao público leitor. De fato, nos textos literários, obras apresentadas como adaptação são mais encontradas em reescritas para públicos específicos, como o infantil ou o juvenil. Ao direcionar uma obra para determinado público, o reescritor pode propor uma série de estratégias de manipulação textual, desde a mera facilitação ou simplificação do texto para torná-lo compreensível até uma transformação de caráter predominantemente estético ou literário, ainda que não deixe de cumprir o requisito da acessibilidade ao texto. Dessa forma, é preciso notar uma ambivalência no termo, pois uma adaptação, embora, por um lado, possa sofrer certo desprestígio por ser considerada uma obra menos representativa de um texto fonte, tendo às vezes um caráter funcional mais evidente, por outro lado, pode vir a ser assim classificada para designar (ou se apresentar como) um trabalho mais autoral. Esse segundo caso ocorre via de regra quando o reescritor tem prestígio no sistema literário/tradutório da cultura meta, recebendo assim uma chancela para oferecer uma nova leitura de determinada obra, podendo 192 inclusive fazer jus a direitos autorais pelo trabalho realizado, o que nem sempre ocorre quando se trata de uma tradução.

Não obstante, conforme aponta Amorim, "se falar de tradução e de adaptação parece sinalizar para duas vias distintas, que seguem caminhos diversos, logo adiante elas se encontram, trazendo à tona o contato entre suas margens e os conflitos decorrentes dele" (AMORIM, 2005, p. 228). Há sempre, portanto, um transbordamento entre as fronteiras fragilmente estabelecidas entre tradução, adaptação, reconto, história recontada, especialmente na área de LIJ, em que esses termos têm sido amplamente empregados. Se a porosidade dos termos já se revela na tentativa de sua própria conceituação (uma vez que toda tradução implica algum tipo ou grau de adaptação e vice-versa), quando lidamos com as reescritas concretas podemos perceber o problema em sua dimensão real. Assim,

[a] presença dos termos "tradução", "adaptação" ou "história recontada" na capa ou na folha de rosto de uma obra não é uma ocorrência destituída de relações: sua significação resulta de uma conexão mais ampla que se estabelece entre fatores diversos, tais como o conceito de tradução e o de adaptação vigentes em uma determinada época; a articulação entre a figura do tradutor ou adaptador responsável pelo texto e os paratextos ou prefácios que enfocam o resultado de seu trabalho; o lugar que ocupa a obra traduzida ente os valores da literatura local; e o próprio objetivo mercadológico da editora. Desse modo, aquilo que se produz, textualmente, sob esses termos não segue uma regra sistemática que indicaria, em todos os casos, uma relação unívoca ou contínua entre o termo que se apresenta na capa e o texto 
“traduzido" ou "adaptado" propriamente dito. (AMORIM, 2005, p. 47).

Por isso, a separação dicotômica usualmente associada aos termos (tradução, enquanto obra mais próxima ao texto fonte, e adaptação, enquanto obra que se distancia deste) não pode ser considerada sem que se observe casos e culturas específicos em que são feitas tais reescritas; isto é, não se pode desconsiderar o contexto, a perspectiva histórica e as concepções acerca dos próprios termos (tradução, adaptação, história recontada, etc.) existentes em dada cultura. Ao menos duas razões para essa ponderação podem ser apontadas: em primeiro lugar, considerando o entendimento padrão para os termos, é necessário verificar como são utilizados concretamente em cada caso e, em segundo lugar, em que medida reescritas apresentadas de modo distinto (tradução, adaptação, história recontada) propõem leituras distintas de uma mesma obra.

No artigo "Translation and Rewriting: Don't translators 'adapt' when they 'translate'?", Azenha e Moreira (2012) problematizam justamente essas definições tratando da questão da adaptação ou história recontada em oposição à tradução. Em que medida diferem uma e outra forma de apresentação de uma reescrita? Para discutir a questão, os autores escolhem a história recontada de A Saga de Siegfried por Tatiana Belinky, voltada ao público infantojuvenil, utilizam o texto fonte alemão e fazem eles próprios uma tradução da obra, objetivando a comparação entre essas duas formas de reescrita.

Trazendo aqui apenas um exemplo do estudo, os autores comentam que, embora o rótulo "história recontada" da reescrita de Tatiana Belinky pareça implicar maior liberdade, a autora/reescritora opta por manter a estrangeiridade do texto, sem realizar alterações do contexto original, e utiliza um recurso como suporte à manutenção do "estrangeiro", um posfácio delineando o contexto histórico cultural da obra. O posfácio exerce uma função didática, com explicações sobre a origem de mitos e a mentalidade da nobreza medieval. E, sobretudo, é no espaço do posfácio que, em consonância com os tempos atuais, Belinky faz uma releitura do texto fonte; questionando o clichê do herói virtuoso, ela comenta:

É curioso notar, no entanto, que em momento algum da narrativa da saga de Nibelung aparece uma só palavra de crítica ou reprovação do narrador à ação do puro Siegfried, quando, para ajudar seu amigo, o rei Gunther, ele derrota, invisível, a invencível e orgulhosa Brunhilde, ludibriando-a de maneira nada menos que desleal, para, mais tarde, não só desmentir e desautorizar a palavra de sua esposa amada Kriemhilde, como mentir, negando o fato, até sob juramento falso - coisa inconcebível para um homem de honra, um guerreiro de sangue real. Não há dúvida de que, se o estratagema tivesse sido usado para enganar e derrotar um adversário masculino, esse fato teria manchado a notável reputação do herói. De onde se conclui que, naqueles tempos de tanta ética, enganar uma mulher, mesmo sendo uma rainha guerreira, não constituía falta grave, capaz de empanar o brilho da honra de um homem. E Siegfried passou 
para a história como um herói perfeito, 'sans peur et sans reproche', paradigma do Held exemplar, digno de ser admirado e amado sem restrições. $\mathrm{O}$ que não deixa de ser um tema para um momento de reflexão. (BELINKY, 2011, p. 31)

Azenha e Moreira comentam que a reescritora poderia ter feito modificações em sua "história recontada", porém opta por realizar um trabalho que seria característico do que se entende como tradução, apresentando uma leitura contemporânea da obra apenas no posfácio, no qual "é interessante notar que ela se refere ao narrador como uma terceira pessoa, como se ela, que está recontando a história, não tivesse poder para relativizar o caráter do herói na própria tradução" (AZENHA; MOREIRA, 2012, p. 70). A estratégia da reescritora foi portanto a de manter o elemento arcaico e estrangeiro no texto sem interferir na descrição do personagem, apresentando sua visão contemporânea sobre o mesmo apenas posteriormente, no posfácio. Assim, comparando a história recontada por Belinky com a tradução feita pelos autores, poucas diferenças são encontradas em termos de enredo. A maior diferença observada refere-se à estruturação desse enredo: a reescrita de Belinky é mais concisa, com foco maior nos eventos do que nos detalhes (AZENHA; MOREIRA, 2012, p. 71), prioriza a narração em 194 detrimento da descrição (p.73), enfatiza a narração de eventos e adota uma postura explanatória em relação ao enredo (p.73). Com a supressão de detalhes, algumas especificidades locais são apagadas, e a história recontada adquire um caráter mais universal, por exemplo, com a omissão de elementos da vida cotidiana (vestuário) específicos da cultura germânica ao longo dos séculos XI a XIII (p. 74).

Esse estudo de caso corrobora a ideia de que, quando se trata de LIJ, as próprias características do gênero, relacionadas ao público alvo e não a aspectos distintivos intrínsecos ao texto, fazem com que fracassem as tentativas de distinção entre tradução e adaptação, ao menos em termos teóricos (AZENHA; MOREIRA, 2012, p. 66). Assim, do ponto de vista teórico não é possível definir tradução e adaptação como categorias excludentes, impermeáveis a contaminação ou conflito, mas sim como instâncias complementares, que ocorrem no processo tradutório. Azenha e Moreira ressaltam, por fim, que há uma interpenetração dos dois processos, tradução e adaptação, e que a decisão de como uma reescrita será rotulada é motivada por questões mercadológicas (AZENHA; MOREIRA, 2012, p. 78).

Dada a ambiguidade dos termos, a porosidade de seus limites e as interpretações distintas de acordo com a cultura em que se inserem, possíveis diferenças entre uma conceituação ou outra precisam ser analisadas com a investigação de cada caso, levando em 
consideração que não haverá categorias estanques predefinidas em que seja possível enquadrar as reescritas sem uma problematização dos termos.

Por fim, vejamos um último caso, para ilustrar essa questão. Duas reescritas brasileiras de uma obra integrante do cânone da LIJ, Alice no país das maravilhas de Lewis Carroll, podem ser aqui abordadas. Apresentadas como tradução, a reescrita de Maria Luiza Borges, com introdução e notas de Martin Gardner, publicada pela Zahar em 2013, e a reescrita de Jorge Furtado e Liziane Kugland, publicada pela Objetiva em 2008, adotam estratégias muito distintas. Enquanto a primeira mantém estreita relação com o texto (e contexto) do autor, a segunda se volta para o contexto de seu público alvo, as crianças brasileiras do século XXI. Ambas trabalham os aspectos da linguagem, linguísticos e semânticos, sem realizar simplificações ou adaptações de caráter instrumental ou didático; entretanto, a tradução de Maria Luiza Borges se completa com os paratextos de Gardner, pois, como o próprio prefaciador explica em uma de suas notas,

\footnotetext{
[e]m sua maioria, os poemas nos dois livros de Alice são paródias de poemas ou canções populares muito conhecidos pelos leitores contemporâneos de Carroll. Com poucas exceções, os originais estão hoje esquecidos, seus títulos só se mantendo vivos porque Carroll resolveu fazer troça deles. Como muito da graça de uma paródia é perdido se não se conhece o que está sendo caricaturado, todos os originais serão reproduzidos nesta edição. (CARROLL, 2013, p. 264).
}

Assim, tanto a edição em inglês organizada por Gardner para o público contemporâneo de língua inglesa como a edição brasileira da Zahar com a tradução de Maria Luiza Borges requerem paratextos para que o leitor de hoje possa ter a compreensão dos trocadilhos e jogos linguísticos criados por Carroll, os quais estão relacionados à época do autor, a Inglaterra vitoriana da segunda metade do século XIX. Já a tradução de Furtado e Kugland, em um processo de domesticação, realiza diversas adaptações, sobretudo nos referidos trocadilhos, jogos linguísticos e paródias, resultando em um texto que transita nas margens do que pode ser considerado adaptação, reconto ou história recontada. Entendendo que a escrita de Carroll emerge do jogo com a linguagem, da exploração da forma, das brincadeiras sonoras e visuais, Furtado e Kugland procedem a uma recriação desses elementos na língua e cultura em que escrevem. Apesar das grandes modificações em partes do texto, os próprios reescritores, no breve prefácio do livro, enfatizam que seu trabalho é uma tradução integral da obra de Carroll, voltada para o público infantil brasileiro do século XXI.

Um exemplo bastante representativo das diferentes estratégias e resultados alcançados das reescritas pode ser visto na passagem em que Alice, confusa, sem saber se ainda era ela 
mesma, busca recordar o que havia aprendido na escola, afinal, em sua lógica, a única forma de garantir que "ela era ela mesma" seria se tivesse os seus conhecimentos. Para isso recita, mas as palavras não vieram como costumavam vir, como vemos a seguir no texto fonte e na tradução de Maria Luiza Borges:

$\begin{array}{ll}\begin{array}{l}\text { How doth the little crocodile } \\ \text { Improve his shining tail } \\ \text { And pour the waters of the Nile } \\ \text { On every golden scale! }\end{array} & \begin{array}{l}\text { Como pode o crocodilo } \\ \text { Fazer sua cauda luzir } \\ \text { Borrifando a água do Nilo } \\ \text { Que dourada vem cair? }\end{array} \\ \text { How cheerfully he seems to grin, } & \text { Sorriso largo, vai nadando, } \\ \text { How neatly spreads his claws, } & \text { E de manso, enquanto nada, } \\ \text { And welcomes little fishes in, } & \text { Os peixinhos vai papando } \\ \text { With gently smiling jaws! } & \text { Co'a bocarra escancarada! } \\ \text { (CARROLL, 2012, p.15) } & \text { (CARROLL, 2013, p. 19) }\end{array}$

O público leitor de hoje só irá perceber a paródia ao ler a nota explicativa de Gardner, conhecendo assim na íntegra o poema de Isaac Watts (1674-1748), “Against Idleness and Mischief", a partir do qual Carroll cria o confuso poema recitado por Alice. Já Furtado e Kugland optam por fazer uma paródia que não necessite de explicação em paratextos, interpolando um breve poema da tradição oral brasileira (batatinha quando nasce) a situações vivenciadas por Alice:

\author{
Batatinha quando nasce \\ Come bolo de montão \\ Menininha quando cresce \\ Fica presa no salão. \\ (CARROLL, 2008, p. 25)
}

O caso de Alice é emblemático porque a escrita de Carroll leva ao ápice uma questão presente em qualquer obra. Como aponta Gardner, "muitos personagens e episódios em Alice são resultado direto de trocadilhos e outros jogos linguísticos, e teriam assumido formas completamente diversas se Carroll estivesse escrevendo, digamos, em francês" (CARROLL, 2013, p.ix). Cada obra, escrita ou reescrita, é o resultado de possibilidades linguísticas do idioma em que se escreve bem como das experiências, em termos socioculturais, de quem escreve. Assim, as duas traduções mencionadas complexificam a discussão: a tradução de Furtado e Kugland sob uma primeira perspectiva se mostra mais afastada do texto fonte, tal como seria uma adaptação. Não obstante, se a perspectiva for a do trabalho com a língua e a 
linguagem, tal como faz Carroll com sua obra, a reescrita de Furtado e Kugland pode ser de fato compreendida como tradução, ao propor, da mesma forma que o autor inglês, jogos de linguagem compreensíveis a seu público leitor, sem necessitar de qualquer aparato exterior ao texto.

A questão da relação entre público alvo e obra exerce um fator determinante nas propostas dos editores e reescritores. Gardner, por exemplo, afirma que "[é] apenas porque adultos - cientistas e matemáticos em particular - continuam a apreciá-los que os livros de Alice têm sua imortalidade assegurada. É apenas para esses adultos que as notas deste volume são dirigidas" (CARROLL, 2013, p.viii). Desse modo, a tradução de Maria Luiza Borges volta-se a um público adulto, uma vez que para a ampla compreensão do texto é necessário ler as notas. Já Furtado \& Kugland, ao contrário, voltam-se para as crianças brasileiras do século XXI, como já mencionado.

Nesse sentido, reescritas como as de Alice, aqui mencionadas, tornam ainda mais instáveis as fronteiras entre as noções de tradução e adaptação relativas à prática tradutória, vistas com frequência no discurso de reescritores e de organizadores das obras literárias. As definições das obras (tradução, adaptação, reconto ou história recontada), portanto, não seguem um padrão ou critério unívoco, sendo uma forma de designação dada pelas editoras ou pelos reescritores de acordo com propostas de patronagem ou poéticas, tais como a própria forma desejada de visibilidade de um reescritor no sistema literário/tradutório em que atua. A utilização dos termos reconto ou história recontada pode apenas servir para dar a chancela ao reescritor de se colocar como o autor do texto com a liberdade de contar da sua forma a história. Essa forma, entretanto, pode não representar uma proposta de nova leitura da obra.

\section{REFERÊNCIAS BIBLIOGRÁFICAS}

AMORIM, Lauro Maia. Tradução e adaptação: encruzilhadas da textualidade em Alice no País das Maravilhas, de Lewis Carroll, e Kim, de Rudyard Kipling. São Paulo: UNESP, 2005.

AZENHA JUNIOR, João. "Tradução e Literatura Infantil e Juvenil". In: AMORIM, Lauro et al. (Org.) Tradução \& Perspectivas Teóricas e Práticas. São Paulo: Unesp, 2015. p. 209-232.

AZENHA JUNIOR, João. "A tradução para a criança e para o jovem: a prática como base da reflexão e da relação profissional". In: Pandaemonium germanicum. São Paulo: USP, v. 9, p. 367-392, 2005.

AZENHA JUNIOR, João; MOREIRA, Marcelo. “Translation and Rewriting: Don't translators 'adapt' when they 'translate'?" In: RAW, Lawrence (Org.). Translation, Adaptation and Transformation. London: Continuum, p. 61-80, 2012. v. 1. 
BELINKY, Tatiana. A Saga de Siegfried: o tesouro dos nibelungos. Recontada por Tatiana Belinky. Ilustrada por Odilon Moraes. $6^{a}$ reimpressão. São Paulo: Companhia das Letrinhas, 2011.

CARROLL, Lewis. Alice: Aventuras de Alice no País das Maravilhas \& Através do Espelho. Ilustrações originais: John Tenniel. Introdução e notas de Martin Gardner. Tradução de Maria Luiza X. de A. Borges. 2. ed. Rio de Janeiro: Zahar, 2013.

CARROLL, Lewis. Alice's Adventures In Wonderland \& Through The Looking-Glass, and What Alice Found There. London: Penguin, 2012.

CARROLL, Lewis. Aventuras de Alice no País das Maravilhas. Tradução de Jorge Furtado e Liziane Kugland. Rio de Janeiro: Objetiva, 2008.

FOWLER, Edward. "Rendering Words, Traversing Cultures: On the Art and Politics of Translating Modern Japanese Fiction”. In: Journal of Japanese Studies, Seattle: Society for Japanese Studies, v. 18, n.1, p. 1-44, 1992.

HUNT, Peter. Crítica, Teoria e Literatura Infantil. Tradução de Cid Knipel. $1^{\text {a }}$ reimpressão. São Paulo: Cosac Naify, 2013.

LEFEVERE, André. Translation, Rewriting, and the Manipulation of Literary Fame.

London: Routledge, 1992.

MACHADO, Ana Maria. Ponto de fuga: conversa sobre livros. São Paulo: Companhia das Letras, 2016.

MEIRELES, Cecília. Problemas da Literatura Infantil. 4. ed. São Paulo: Summus, 2016. MILTON, John. As traduções do Clube do Livro. In: Revista TradTerm, São Paulo: USP, v. 3., p. 47-65, 1996.

REIS, Roberto. “Cânon”. In: JOBIM, José Luís. Palavras da Crítica. Tendências e conceitos no estudo da Literatura. Rio de Janeiro: Imago, 1992. p. 65-92.

SHAVIT, Zohar. "Translation of Children's Literature". In: LATHEY, Gillian. The Translation of Children's Literature: A Reader. UK: Multilingualmatters, 2006. p. 25-40.

VENUTI, Lawrence. "A formação de identidades culturais". In: VENUTI, Lawrence. Escândalos da Tradução. Tradução de Laureano Pelegrin, Lucinéia Marcelino Villela, Marileide Dias Esqueda e Valéria Biondo. Bauru, São Paulo: EDUSC, 2002. p. 129-167.

WOZNIAK, Monika. "Where (and) When Do You Live, Cinderella? Cultural Shifts in Polish Translations and Adaptations of Charles Perrault's Fairy Tales". In: LEFEBVRE, Benjamin (Ed.). Textual transformations in children's literature: adaptations, translations, reconsiderations. New York/London: Routledge, 2013. p. 87-100.

ZILBERMAN, Regina. A literatura infantil na escola. 11. ed. São Paulo: Global, 2003. 


\footnotetext{
* Anna Olga Prudente de OLIVEIRA - Doutora (2018) e mestre (2014) em Estudos da Linguagem pela Pontifícia Universidade Católica do Rio de Janeiro. Graduada em Letras (2011) pela Pontifícia Universidade Católica do Rio de Janeiro e em Artes Cênicas pela Universidade Federal do Estado do Rio de Janeiro. Pós-doutoranda na Universidade Federal do Paraná. Curitiba, Paraná, Brasil.

Currículo Acadêmico: http://lattes.cnpq.br/2830719661155260

ORCID: https://orcid.org/0000-0001-6480-0654

E-mail: annaolga@terra.com.br

${ }^{1}$ Para uma discussão sobre a questão do processo de individualização da criança e o consequente desenvolvimento do conceito de infância, ver: GÉLIS, Jacques. "A individualização da criança” (In: História da vida privada, 3: da Renascença ao Século das Luzes. ARIẼS, Philippe; CHARTIER, Roger (ed.) Tradução: Hildegard Feist. 6 reimpressão. São Paulo, Companhia das Letras, 1997. p. 311-330); e BRYSON, Bill. "O quarto das crianças" (In: BRYSON, Bill. Em casa: uma breve história da vida doméstica. Tradução de Isa Mara Lando. São Paulo: Companhia das Letras, 2010. p. 429-468).

1 "the very notion of an international canon of classic fairy tales is deceptive, given the numerous divergences that can be detected in terms of nation, culture, language, style, selection, and story." (WOZNIAK, 2013, p. 88)

2 "Even though it is regrettable that a critical that a critical edition of Perrault's works in Poland has not yet been published, the singular case of Polish reception of his tales may be interpreted as a fascinating and singular case of the nationalization of classic fairy tales.” (WOZNIAK, 2013, p. 96)

3 "an adjustment of the text to make it appropriate and useful to the child, in accordance with what society regards (at a certain point in time) as educationally 'good for the child'; and an adjustment of plot, characterization, and language to prevailing society's perceptions of the child's ability to read and comprehend." (SHAVIT, 2006, p. 26)
} 